\title{
Cognitive Impairment and Memory Loss in Diabetes: A Myth or Reality
}

\author{
Madeeha Malik ${ }^{1, *}$, Sidra Bí2 ${ }^{2}$ Azhar Hussain ${ }^{3}$ \\ ${ }^{1}$ Professor, Hamdard Institute of Pharmaceutical Sciences, Hamdard University, Islamabad Campus, PAKISTAN \\ ${ }^{2}$ M.Phil Scholar Hamdard Institute of Pharmaceutical Sciences, Hamdard University, Islamabad Campus, PAKISTAN \\ ${ }^{3}$ Dean of Faculty of Pharmacy, Hamdard University, Islamabad Campus, PAKISTAN
}

Received: 11 December 2018;

Accepted: 21 January 2019

*Correspondence to:

Prof. Madeeha Malik,

Vice President, Pakistan Society of Pharmacy

Practicel Professor, Hamdard Institute of

Pharmaceutical Sciences, Hamdard University, Islamabad Campus, PAKISTAN.

Email: madeehamalik15@gmail.com

Copyright: (c) the author(s),publisher and licensee Indian Academy of Pharmacists. This is an open-access article distributed under the terms of the Creative Commons Attribution Non-Commercial License, which permits unrestricted non-commercial use, distribution, and reproduction in any medium, provided the original work is properly cited.

\begin{abstract}
Diabetes itself might not be a risk factor but mismanagement and poor control of disease may lead to the problem. High blood glucose levels, elevated blood pressure, obesity and high cholesterol collectively lead to complications including decline in cognitive ability. The present study was designed to explore the factors effecting cognitive impairment and memory loss among diabetes patients in twin cities of Pakistan. A descriptive cross-sectional study design was used. A pre-validated data collection tool i.e. Mini Mental State Examination (MMSE) questionnaire, which is a practical method for grading the cognitive state of patients was distributed to a sample of 386 diabetes patients. After data collection the data was cleaned, coded and statistically analyzed using SPSS version 21 . Out of 386 respondents $97.75 \%(n=377)$ had normal cognition level, $2.3 \%(n=9)$ had mild decline in cognition level while none of the respondents had moderate or severe cognitive impairment. Significant association for cognitive impairment and demographic variables such as gender ( $p=0.006$ ) was observed. However, no significant association for cognitive impairment was observed for age, qualification, duration and type of disease, class of medication, income level, control of disease and medication adherence. The present study concluded that majority of the diabetes patients did not show cognitive impairment and memory loss. However, mild cognitive decline was observed among males, elderly and more common in type II diabetes patients. Better qualification and income can improve knowledge, adherence and disease appraisal resulting in better approach towards management of disease. This in turn can positively affect cognition and memory loss. Thus, it can be assumed that diabetes might not directly play major role in cognitive impairment and memory loss but its poor management may affect psychomotor functions of the patients.
\end{abstract}

Key words: Cognitive impairment, Memory loss, Diabetes, Pakistan.

\section{INTRODUCTION}

According to the International Diabetes Federation, diabetes affects at least 382 million people worldwide and this number is expected to reach 592 million by the year 2035. ${ }^{[1]}$ A systematic review in China based on age related cognitive decline provided an estimation of cognitive decline which shows that 35.6 million people worldwide were living with dementia and mild cognitive impairment in 2010 and this number is projected nearly to double every 20 years. Diabetes itself might not be a risk factor but mismanagement and poor control of disease may lead to the problem. High blood glucose levels, elevated blood pressure, obesity and high cholesterol collectively lead to complications including decline in cognitive ability. ${ }^{[2]}$ Appraisal of diabetes associated cognitive impairment and memory loss can help to improve symptoms of impairment and management can delay the consequences. Early identification of Cognitive Impairment (CI) and memory loss allows for timely prevention and better prognosis for patients and their caretakers. However, effective approach to identify cognitively impaired patients from community for interventions is not enough, due to lack of routine cognitive screening. ${ }^{[3]}$

Diabetes patients with poor glycemic control usually show decline in neurocognitive function with increase in age. In past, this was not an issue because patients with type I diabetes died at relatively young age from other complications of the disease and were not reported for cognitive dysfunction. ${ }^{[4]}$ Nevertheless, now patients with type I diabetes as well as type II live longer and cope up better with the disease. However, cognitive dysfunction is usually still not tested in routine assessment. ${ }^{\left[{ }^{[}\right]}$Although, latest trends in better imaging biomarkers have evolved but still they have not been incorporated in routine practice for better management of chronic diseases in many developing countries including Pakistan. Assessment of risk factors and identification of the mechanisms and pathophysiology through which risk factors may impair cognitive function in patients with diabetes is still an unexplored area which needs to be addressed for better management of disease resulting in improved health related quality of life among diabetes patients. Thus, the present study was designed to explore the factors effecting cognitive impairment and memory loss among diabetes patients in twin cities of Pakistan.

\section{MATERIALS AND METHODS}

Method

A descriptive cross-sectional study design was used to explore the factors effecting cognitive impairment and memory loss among diabetes patients in twin cities i.e. Islamabad (Federal Capital) and Rawalpindi (Twin City) of 
Pakistan. Study sites for this research included public and private tertiary health care facilities and diabetes clinics located in twin cities of Pakistan. Study respondents included in the study were: any diabetes patient (type I or II) with duration of disease at least one year, getting their treatment from any usual care setting (hospital, clinic, community centre), persons who were between 20-75 years old, both genders (Male vs. Female) and persons who could easily read and write were included in the study. However, diabetes patients previously taking treatment for any other psychological disorder were excluded. Calculation of sample size was performed by Raosoft ${ }^{\circledR}$ sample size calculator to determine the size of sample representing the study population. The calculated sample size was 386 to achieve $95 \%$ confidence interval and $5 \%$ margin of error. Convenient sampling technique was used for the study and all the respondents that were available at the time of data collection and willing to participate in the study were selected.

A pre-validated data collection tool i.e. Mini Mental State Examination (MMSE) questionnaire, which is a practical method for grading the cognitive state of patients was used. Written permission was obtained from the respective organization for using the tool. Mini Mental State Examination (MMSE) is a brief clinical test of mental status that consists of total of eleven questions. The MMSE begins with a graded assessment of orientation to place and time; this is followed by testing two aspects of memory. The first is the immediate recall for three objects presented orally, followed by a serial sevens task which is interposed to assess attention, concentration and calculation and also to prevent the individual from rehearsing the three objects previously learned. The final section surveys aphasia by testing functions of naming, repetition, understanding a three-stage command, reading, writing and copying a drawing. The MMSE can be easily administered by trained health care professional. The person administering the MMSE is required to be receptive about patient embarrassment if patient was unable to answer these questions. Respondents were informed that this is another way of determining how the treatment is affecting their cognitive abilities. Total score of MMSE is 30. A score range of 0-10 indicates severe cognitive impairment, 11-20 score range indicates moderate cognitive impairment, 21-25 indicates mild cognitive impairment while a score of 26-30 shows cognitive impairment of questionable significance. MMSE was self-administered by principal investigator after obtaining written/verbal consent from the respondents. The questionnaire was collected back on the same day to avoid any study biasness. After data collection the data was cleaned, coded and statistically analyzed using SPSS version 21. Descriptive statistics comprising of frequency and percentages were calculated. Chi-Square test $(p \geq 0.05)$ was used to find association among different variables.

\section{RESULTS}

Out of 386 respondents, $56.7 \%(n=219)$ were male while $43.3 \%(n=167)$ were females. The qualification level of the respondents was: secondary ( $\mathrm{n}$ $=96,24.9 \%)$, Intermediate $(n=120,31.1 \%)$, Graduate $(n=122,31.6 \%)$ and master $(n=37,9.6 \%)$. In perspective of their duration of disease, $31.1 \%(n$ $=120)$ were newly diagnosed cases while $6.7 \%(n=26)$ had more than 10 years history of disease. According to types of disease $49.0 \%(n=189)$ were diagnosed with type I disease while $50.5 \%(n=195)$ were type II. Regarding the co morbidities, $35.2 \%(n=136)$ were hypertensive, $7.5 \%(n=29)$ were obese, $4.7 \%(n=22)$ had coronary artery disease, $4.4 \%(n=17)$ were suffering from kidney disease, while $46.6 \%(n=179)$ were free from any kind of co morbidity (Table 1).

Out of 386 respondents $97.75 \%(n=377)$ had normal cognition level, 2.3\% $(n=9)$ had mild decline in cognition level while none of the respondents had moderate or severe cognitive impairment (Table 2).

\begin{tabular}{|c|c|c|}
\hline \multicolumn{2}{|l|}{ Indicators } & \multirow{2}{*}{$\begin{array}{l}\text { Frequency } \mathbf{n}(\%) \\
35(9.1) \\
\end{array}$} \\
\hline Age & $20-30 Y$ & \\
\hline & $31-40 Y$ & $82(21.2)$ \\
\hline & $41-50 Y$ & $114(29.5)$ \\
\hline & $51-60 Y$ & $111(28.8)$ \\
\hline & $61-75 Y$ & $44(11.4)$ \\
\hline \multirow[t]{2}{*}{ Gender } & Male & $219(56.7)$ \\
\hline & Female & $167(43.3)$ \\
\hline \multirow[t]{2}{*}{ Marital Status } & Married & $341(88.3)$ \\
\hline & Unmarried & $45(11.7)$ \\
\hline \multirow[t]{5}{*}{ Level of Qualification } & Secondary & $96(24.9)$ \\
\hline & Intermediate & $120(31.1)$ \\
\hline & Graduate & $122(31.6)$ \\
\hline & Master & $37(9.6)$ \\
\hline & Others & $11(2.8)$ \\
\hline \multirow[t]{4}{*}{ Income group } & $<10-20000$ & $96(24.9)$ \\
\hline & $21,000-35000$ & $189(49.0)$ \\
\hline & $36,000-50,000$ & $62(15.8)$ \\
\hline & $>50000$ & $39(9.8)$ \\
\hline \multirow[t]{4}{*}{ Duration of disease } & $1-2 Y$ & $120(31.1)$ \\
\hline & $5-10 Y$ & $150(38.9)$ \\
\hline & $10-20 \mathrm{Y}$ & $90(23.3)$ \\
\hline & $>20 Y$ & $26(6.7)$ \\
\hline \multirow[t]{2}{*}{ Type of disease } & Type I & $190(49.0)$ \\
\hline & Type II & $196(50.5)$ \\
\hline \multirow[t]{6}{*}{ Class of Medication uses } & Insulin & $186(48.2)$ \\
\hline & Biguanides & $43(11.1)$ \\
\hline & Sulfonylureas & $29(7.5)$ \\
\hline & DPP4 inhibitors & $32(8.3)$ \\
\hline & Incretins & $89(23.1)$ \\
\hline & Combination & $7(1.8)$ \\
\hline \multirow[t]{6}{*}{ Co-morbidity } & Hypertension & $136(35.2)$ \\
\hline & CKD & $17(4.4)$ \\
\hline & CVD & $22(5.7)$ \\
\hline & Obesity & $29(7.5)$ \\
\hline & Any other & $03(0.8)$ \\
\hline & None & $179(46.6)$ \\
\hline \multirow[t]{2}{*}{ Diabetes control } & $\mathrm{HbA} 1 \mathrm{c}$ not done & $264(68.4)$ \\
\hline & HbA1c done & $122(31.3)$ \\
\hline \multirow[t]{2}{*}{ Residence } & Rural & $156(40.8)$ \\
\hline & Urban & $226(59.2)$ \\
\hline \multirow{2}{*}{$\begin{array}{l}\text { Medication } \\
\text { taken regularly }\end{array}$} & yes & $121(31.3)$ \\
\hline & No & $265(68.4)$ \\
\hline
\end{tabular}

\begin{tabular}{|c|c|}
\hline Interpretation & n (\%) \\
\hline Questionably significant (26-30) & $377(97.7)$ \\
\hline Mild (21-25) & $9(2.3)$ \\
\hline Moderate (11-20) & 0 \\
\hline Severe $(0-10)$ & 0 \\
\hline
\end{tabular}


Out of 386 respondents $48.9 \%(n=189)$ were reported with type I diabetes, $2.11 \%(n=4)$ of them showed mild decline in cognition. On the other hand $50.5 \%(n=195)$ participants were reported with type II diabetes, out of which $2.56 \%(n=5)$ showed mild cognitive decline. Thirty one percent of the total patients were newly diagnosed, out of which $2.33 \%(n=9)$ respondents were reported with mild cognitive decline. However, $38.8 \%(n=150)$ participants were reported with 2 years of disease, $2 \%(n=3)$ of them showed mild decline in their cognitive functions. Furthermore, 96.6\% $(n=87)$ respondents were reported with 5-10 years of disease, out of which $3.33 \%(n=3)$ participants showed mild cognitive decline. No significant association $(p \leq 0.05)$ was observed in cognitive impairment and memory loss among different type and duration of diabetes patients (Table 3).

Out of 386 respondents $48.1 \%(n=186)$ were taking insulin, out of which, $2.1 \%(n=4)$ respondents were reported with mild cognitive impairment. On the other hand $51.8 \%(n=200)$ respondents were on oral anti-diabetic agents and $2.5 \%(n=5)$ of them reported with mild cognitive impairment. No significant association $(p \leq 0.05)$ was observed in cognitive impairment and memory loss among diabetes patients taking different medications (Table 4).

Significant association for cognitive impairment and demographic variables such as gender $(p=0.006)$ was observed. However, no significant association for cognitive impairment was observed for age, qualification, income level, control of disease and medication adherence (Table 5).

\section{DISCUSSION}

Diabetes mellitus has remained a major problem worldwide resulting in increased morbidity, mortality and burden on society. Due to prolonged

\begin{tabular}{|c|c|c|c|c|}
\hline \multirow[t]{2}{*}{ Variable } & \multicolumn{4}{|c|}{ Interpretation of MMSE } \\
\hline & $\begin{array}{l}\text { Mild (21-25) } \\
n(\%)\end{array}$ & $\begin{array}{l}\text { Questionably } \\
\text { significance } \\
(26-30) \text { n (\%) }\end{array}$ & $\begin{array}{l}\text { Total } n \\
(\%)\end{array}$ & $P$-value \\
\hline \multicolumn{5}{|l|}{ Type of Diabetes } \\
\hline Type I & $4(2.11)$ & $185(97.8)$ & $189(48.9)$ & \multirow{3}{*}{0.876} \\
\hline Type II & $5(2.56)$ & $190(97.4)$ & $195(50.5)$ & \\
\hline Total & $9(2.33)$ & $375(97.6)$ & 386 & \\
\hline \multicolumn{5}{|c|}{ Duration of Diabetes } \\
\hline Newly diagnosed & $3(2.5)$ & $117(97.5)$ & $120(31.0)$ & \multirow{5}{*}{0.848} \\
\hline $1-2 Y$ & $3(2.0)$ & $147(98.0)$ & $150(38.8)$ & \\
\hline $5-10 Y$ & $3(3.33)$ & $87(96.6)$ & $90(23.3)$ & \\
\hline$>10 Y$ & $0(0.00)$ & $26(100.0)$ & $26(6.7)$ & \\
\hline Total & $9(2.33)$ & 377 (97.6) & 386 & \\
\hline
\end{tabular}

Chi square test $(p \leq 0.05)$

\begin{tabular}{|c|c|c|c|c|}
\hline \multirow{2}{*}{$\begin{array}{l}\text { Variable } \\
\text { Class of } \\
\text { medication }\end{array}$} & \multicolumn{4}{|c|}{ Interpretation of MMSE } \\
\hline & $\begin{array}{l}\text { Mild } \\
(21-25) \\
n(\%)\end{array}$ & $\begin{array}{l}\text { Questionably } \\
\text { significance } \\
(26-30) n(\%)\end{array}$ & $\begin{array}{l}\text { Total } n \\
(\%)\end{array}$ & $P$-value \\
\hline Insulin & $4(2.1)$ & $182(97.8)$ & $186(48.1)$ & \multirow[t]{3}{*}{0.071} \\
\hline $\begin{array}{l}\text { Oral anti-diabetic } \\
\text { agents }\end{array}$ & $5(2.5)$ & $195(97.5)$ & $200(51.8)$ & \\
\hline Total & $9(2.33)$ & 377 (97.6) & 386 & \\
\hline
\end{tabular}

Chi square test $(p \geq 0.05)$

\begin{tabular}{|c|c|c|c|c|c|}
\hline \multicolumn{2}{|c|}{ Indicators } & $\begin{array}{l}\text { Mild } \\
(21-25) \\
n(\%)\end{array}$ & $\begin{array}{l}\text { Questionably } \\
\text { significance } \\
(26-30)\end{array}$ & $\begin{array}{l}\text { Total } \\
n(\%)\end{array}$ & $\begin{array}{l}P \\
\text { value }\end{array}$ \\
\hline \multirow[t]{6}{*}{ Age } & $20-30 Y$ & $1(2.8)$ & $34(97.1)$ & $35(9.06)$ & \multirow{6}{*}{0.392} \\
\hline & $31-40 Y$ & $1(1.21)$ & $81(98.7)$ & $82(21.2)$ & \\
\hline & $41-50 Y$ & $1(0.87)$ & $113(99.1)$ & $114(29.5)$ & \\
\hline & $51-60 Y$ & $5(4.50)$ & $106(95.4)$ & $111(28.7)$ & \\
\hline & $61-75 Y$ & $1(2.27)$ & $43(97.7)$ & 44 (11.39) & \\
\hline & Total & & & 386 & \\
\hline \multirow[t]{3}{*}{ Gender } & Male & $9(4.10)$ & $210(95.8)$ & $219(56.7)$ & \multirow{3}{*}{0.006} \\
\hline & Female & $0(0.00)$ & $167(100.0)$ & $167(43.2)$ & \\
\hline & Total & $9(2.38)$ & 377 (97.6) & 386 & \\
\hline \multirow[t]{6}{*}{ Qualification } & Secondary & $1(0.25)$ & 95 (98.9) & $96(24.8)$ & \multirow{6}{*}{0.208} \\
\hline & Intermediate & $4(3.33)$ & $116(96.6)$ & $120(31.0)$ & \\
\hline & Graduate & $2(1.63)$ & $120(98.3)$ & $122(31.6)$ & \\
\hline & Master & $0(0.00)$ & $37(100)$ & $37(9.58)$ & \\
\hline & Other & $2(18.1)$ & $9(81.8)$ & $11(2.84)$ & \\
\hline & Total & $9(2.33)$ & 377 (97.6) & 386 & \\
\hline \multirow{5}{*}{$\begin{array}{l}\text { Current } \\
\text { Income }\end{array}$} & $<10-20000$ & $5(5.20)$ & $91(94.7)$ & $96(24.8)$ & \multirow{5}{*}{0.130} \\
\hline & $21,000-35000$ & $3(1.58)$ & $186(98.4)$ & $189(48.9)$ & \\
\hline & $36,000-50,000$ & $0(0.00)$ & $61(100.0)$ & $61(15.8)$ & \\
\hline & $>50,000$ & $1(2.63)$ & $37(97.3)$ & $38(9.84)$ & \\
\hline & Total & $9(2.33)$ & 377 (97.6) & 386 & \\
\hline \multirow{3}{*}{$\begin{array}{l}\text { Control of } \\
\text { disease }\end{array}$} & Yes & $5(4.13)$ & 116 (95.8) & $121(31.3)$ & \multirow{3}{*}{0.300} \\
\hline & No & $4(1.51)$ & $260(98.4)$ & $264(68.3)$ & \\
\hline & Total & $9(2.33)$ & 376 (97.4) & 386 & \\
\hline \multirow{3}{*}{$\begin{array}{l}\text { Taking } \\
\text { medicine } \\
\text { regularly }\end{array}$} & Yes & $5(4.13)$ & 116 (95.8) & $121(31.3)$ & \multirow{3}{*}{0.876} \\
\hline & No & $4(1.51)$ & 260 (98.4) & $264(68.3)$ & \\
\hline & Total & $9(2.33)$ & 376 (97.4) & 386 & \\
\hline
\end{tabular}

Chi-square test $(p \geq 0.05)$.

therapy and complications associated to diabetes, physical, mental and social discomforts are common leading towards poor disease outcome. ${ }^{[6]}$ The results of present study reported that majority of the diabetes patients showed no signs of cognitive impairment and dementia. However, mild cognitive impairment and memory loss in elderly diabetes patients was observed. These findings are in accordance to a study conducted in India where the overall prevalence of cognitive decline among diabetes patients was reported low but still diabetes mellitus was found to be a risk factor for cognitive decline and memory loss with weak significance level amongst urban older adults. ${ }^{[7]}$

Lack of access to healthcare facilities, poor disease control and delay in receiving care result in worse outcomes for patients and as well as society. Both conditions, under diagnosed or diagnosed but uncontrolled cases for long duration can decrease the quality of life..$^{[8]}$ The result of present study revealed that type and duration of diabetes may affect cognition and memory. Patients with type II diabetes with longer duration of disease showed mild cognitive impairment and memory loss. This might be linked to the fact that elderly people are more prone towards cognitive decline as supported by the literature. Similar findings with impact of duration of disease on cognition and memory was reported by a study conducted in United Kingdom. ${ }^{[9,10]}$ 
Progressive loss of cognitive performance contributes to intellectual, behavioral and functional declines and an inability to learn. The incidence of mild cognition impairment has been estimated to be $5 \%$ to $20 \%$ among people older than 65 years. ${ }^{[2]}$ However, people with diabetes are more prone towards this issue. Age related decline in cognitive functioning also affects the health-related quality of life among elderly diabetic patients. The results of the present study also support this argument and reported that cognition and memory were mildly impaired in the elder diabetes patients. Similar findings of cognitive decline and memory loss were reported in diabetes patients in America. ${ }^{[1]}$ Males, being the only caretaker and supporter of the family are usually busy. Due to their busy routine they are non-compliant to medication therapy and dietary instructions. The results of the present study showed relatively more mild cognitive impairment and memory loss among male diabetes patients. This might be due to the reason that they don't find out much time for monitoring and disease control. Psychomotor functions are usually assessed to check nerve functioning and its impact on cognition. The results of the present study reported mild decline in Verbal ability and visual perceptions of diabetes patients. These findings are in line with a study conducted in Sweden reporting poor verbal and visual abilities among diabetes patients. ${ }^{[10]}$

Diabetes is a non-communicable disease which can be prevented by following different educational strategies including better communication, dietary approaches, physical activity and guidance towards medication adherence. The present study reported that better qualification and income level among diabetes patients resulted in no severe cognitive impairment and dementia. This might be due to better awareness and access to healthcare services leading to better disease appraisal and treatment outcomes. Similar findings of better impact of qualification and awareness on cognition and memory was reported by a study conducted in Finland..$^{[12-14]}$

Knowledge and awareness about diabetes in Asia, particularly in rural areas, is inadequate. The result of the present study revealed that diabetes patients residing in urban area had no severe cognitive decline and memory loss. This might be due to better understanding and appraisal of disease. Similar findings with impact of urbanization, improved knowledge and access towards better management of disease was reported in India. ${ }^{[15]}$ Medication non adherence is a major public health issues and associated with higher health care costs. Patients with diabetes have two or more co morbidities, they often require multiple medications. The results of the current study highlighted that majority of the diabetes patients did not test their HbA1c as regular practice. Most of them also forget to take medicines regularly. This might be due to the reason that the cost of medication is higher. This careless attitude towards medication compliance reflects mild cognitive impairment and dementia among diabetes patients. Similar findings were reported in a study conducted in USA. ${ }^{[14]}$

\section{CONCLUSION}

The present study concluded that majority of the diabetes patients did not show cognitive impairment and memory loss. However, mild cognitive decline was observed among males, elderly and more common in Type II diabetes patients. Better qualification and income can improve knowledge, adherence and disease appraisal resulting in better approach towards management of disease. This in turn can positively affect cognition and memory loss. Thus, it can be assumed that diabetes might not directly play major role in cognitive impairment and memory loss but its poor management may affect psychomotor functions of the patients. Therefore, screening procedures for cognitive impairment among diabetes patients must be devised to identify patients at increased risk of accelerated cognitive decline at an early disease stage for development of effective individualized treatment regimen.

\section{ACKNOWLEDGEMENT}

None

\section{CONFLICT OF INTEREST}

The authors declare no conflict of interest

\section{ABBREVIATIONS}

Nil

\section{REFERENCES}

1. Li J, et al. Effects of diabetes mellitus on cognitive decline in patients with Alzheimer disease: a systematic review. Canadian Journal of Diabetes. 2017;41(1):114-9.

2. Tsai CK, et al. Increased risk of cognitive impairment in patients with components of metabolic syndrome. Medicine. 2016;95(36).

3. Shaik MA, et al. Risk factors of cognitive impairment and brief cognitive tests to predict cognitive performance determined by a formal neuropsychological evaluation of primary health care patients. Journal of the American Medical Directors Association. 2016;17(4):343-7.

4. McCrimmon RJ, Ryan CM, Frier BM. Diabetes and cognitive dysfunction. The Lancet. 2012;379(9833):2291-9.

5. Biessels GJ, Deary IJ, Ryan CM. Cognition and diabetes: a lifespan perspective. The Lancet Neurology. 2008;7(2):184-90.

6. Biessels GJ, et al. Risk of dementia in diabetes mellitus: a systematic review. The Lancet Neurology. 2006;5(1):64-74.

7. Tiwari S, et al. Diabetes mellitus: A risk factor for cognitive impairment amongst urban older adults. Industrial Psychiatry Journal. 2012;21(1):44.

8. Lustman PJ, et al. Depression and poor glycemic control: a meta-analytic review of the literature. Diabetes care. 2000;23(7):934-42.

9. Ojo O, Brooke J. Evaluating the association between diabetes, cognitive decline and dementia. International Journal of Environmental Research and Public Health. 2015;12(7):8281-94.

10. Brismar $\mathrm{T}$, et al. Predictors of cognitive impairment in type 1 diabetes. Psychoneuroendocrinology. 2007;32(8):1041-51.

11. Yaffe $\mathrm{K}$, et al. Diabetes, glucose control and 9-year cognitive decline among older adults without dementia. Archives of Neurology. 2012;69(9):1170-5.

12. Ngandu $\mathrm{T}$, et al. A 2 year multidomain intervention of diet, exercise, cognitive training and vascular risk monitoring versus control to prevent cognitive decline in at-risk elderly people (FINGER): a randomised controlled trial. The Lancet. 2015;385(9984):2255-63.

13. Sankar UV, et al. The adherence to medications in diabetic patients in rural Kerala, India. Asia Pacific Journal of Public Health. 2015;27(2):NP513-23.

14. Kirkman MS, et al. Determinants of adherence to diabetes medications: findings from a large pharmacy claims database. Diabetes Care. 2015;38(4):604-9.

15. Hussain $\mathrm{R}$, et al. Knowledge and awareness about diabetes mellitus and diabetic retinopathy in suburban population of a south Indian state and its practice among the patients with diabetes mellitus: a population-based study. Indian Journal of Ophthalmology. 2016;64(4):272.

Cite this article as: Malik M, Bi S, Hussain A. Cognitive Impairment and Memory Loss in Diabetes: A Myth or Reality. J Pharm Pract Community Med. 2019;5(1):31-4. 